\title{
SISTEM KONTROL INFORMASI AKTIVITAS LANSIA BERBASIS INTERNET OF THINGS (IOT)
}

\author{
Pujianti Wahyuningsih \\ uji.wahyuningsih@gmail.com \\ STMIK Handayani Makassar
}

\begin{abstract}
Abstrak
Manusia lanjut usia atau lansia adalah fase dimana manusia tidak dapat melakukan banyak aktivitas karena faktor fisik dan usia. Dalam melakukan aktivitas sehari-hari lansia harus di jaga oleh keluarga atau perawat sehingga pada penelitian ini akan dibangun sebuah sistem kontrol yang dapat mendeteksi aktivitas lansia dan mengontrol peralatan elektronik dari jarak jauh menggunakan Internet of Things (IoT). Semua aktivitas lansia di deteksi berdasarkan input data sensor dari karpet, sensor PIR dan sensor suhu DHT22 kemudian diproses oleh Arduino Mega dan Raspberry Pi. Fungsi Raspberry $\mathrm{Pi}$ adalah untuk menghubungkan semua informasi data ke internet menggunakan node.js. Berdasarkan informasi tersebut keluarga atau perawat dapat melihat aktivitas lansia dari jarak jauh melalui website kemudian dapat mengontrol peralatan elektronik berupa kipas dan pemanas secara manual dan otomatis menggunakan teknologi Internet of Things.
\end{abstract}

Kata kunci: Lansia, Sistem Kontrol, Internet of Things (IoT)

\section{Abstract}

Elderly is a human phase are notabel to much do an activity because of physical factors and age. On doing daily activity the elderly should be kept by the family or nurse so in this research will be built a control system thatabel to detection of elderly activity and control an electronic device remotely using the Internet of Things (IOT). All of the elderly activity has detected based on sensor data input from the carpet, PIR sensor, DHT22 temperature sensor then processed in the Arduino Mega and Raspberry $\mathrm{Pi}$. The function of Raspberry $\mathrm{Pi}$ is to connect all elderly information to the internet using node.js. Based on the information the family or nurse able to see the elderly activity remotely using website and able to control electronic device like a fan and heater by manually and automatically using the Internet of Things technology.

Keywords: Elderly, Control Systems, Internet of Things (IoT)

\section{Pendahuluan}

Lansia (Lanjut Usia) merupakan fase kehidupan manusia yang tidak dapat melakukan banyak aktivitas karena keterbatasan fisik dan usia. Hampir seluruh aktivitas lansia harus dipantau oleh keluarga atau perawat karena khawatir terjadi sesuatu yang tidak diinginkan pada lansia. Salah satu cara yang dilakukan oleh keluarga untuk terus menjaga lansia adalah dengan memberikan handphone kepada lansia, ini dilakukan ketika keluarga atau penjaga lansia sedang berada di luar karena sesuatu hal yang mendesak sehingga harus meninggalkan lansia sendirian di rumah. Namun cara tersebut masih mempunyai kekurangan yaitu pada saat lansia melakukan aktivitas lupa membawa ponsel atau mungkin dalam keadaan tidak aktif bahkan tidak mempunyai pulsa. Banyaknya aktivitas keluarga yang dilakukan di luar rumah membuat mereka selalu merasa khawatir dan waswas dengan aktivitas yang dilakukan oleh lansia di rumah. Ini akan menjadi masalah ketika penjaga lansia memiliki aktivitas penting di luar rumah dan harus meninggalkan lansia sendirian. Berdasarkan permasalahan tersebut peneliti membangun sebuah sistem kontrol yang dapat memberikan informasi aktivitas lansia kepada keluarga atau penjaga lansia serta dapat mengontrol peralatan elektronik dari jarak jauh menggunakan teknologi loT.

Pada penelitian yang telah dilakukan sebelumnya, peneliti telah membangun sebuah sistem pendeteksi aktivitas lansia yang berada di atas karpet pada saat sedang berdiri, berjalan, duduk dan berbaring, namun belum mengembangkan sistem pengontrolan suhu dan kipas dari jarak jauh agar lansia merasa lebih nyaman ketika berada dalam satu ruangan [1]. Selain itu peneliti juga telah melakukan analisa dari efektifitas penggunaan algoritma greedy dalam mendeteksi aktivitas lansia di atas karpet [2]. Berdasarkan penelitian yang telah dilakukan sebelumnya maka peneliti akan mengembangkan sebuah sistem kontrol yang dapat memberikan informasi aktivitas lansia berbasis IoT. Dalam penelitian ini informasi aktivitas lansia akan dikirim secara realtime menggunakan jaringan koneksi internet dan dapat diakses melalui website, selain itu penjaga lansia juga dapat melihat 
kondisi suhu ruangan serta dapat mengontrol nyala kipas dan pemanas secara manual dan otomatis dari jarak jauh menggunakan teknologi loT.

\section{Metode}

\subsection{Lansia}

Setiap manusia yang berumur panjang pasti akan melewati fase berumur tua hingga puluhan bahkan ratusan tahun dan biasa disebut sebagai lansia. Lansia adalah tahap akhir dari siklus hidup manusia, dimana manusia tersebut pastinya akan mengalami perubahan baik secara fisik maupun mental. Kategori umur lansia adalah diatas 60 tahun [3][4], proses penuaan merupakan proses alami yang dapat menyebabkan perubahan anatomis, fisiologis, dan biokimia pada jaringan tubuh yang dapat mempengaruhi fungsi, kemampuan badan dan jiwa [5]. Pada lansia penurunan fungsi kognitif adalah keadaan normal yang akan dialami oleh lansia, namun keadaan ini dapat diatasi dan di hambat dengan cara meningkatkan aktivitas fisik lansia [4]. Kurangnya konsentrasi lansia saat beraktivitas akan mengakibatkan lansia mengalami kecelakaan atau sesuatu yang tidak diinginkan sehingga dapat membahayakan diri bahkan nyawa lansia.

\subsection{Sistem Desain}

Pada sistem yang akan dibangun terdapat rancangan layout yang didesain, berikut adalah rancangan layout dari sistem yang akan dibangun dari sistem informasi aktivitas lansia berbasis loT.

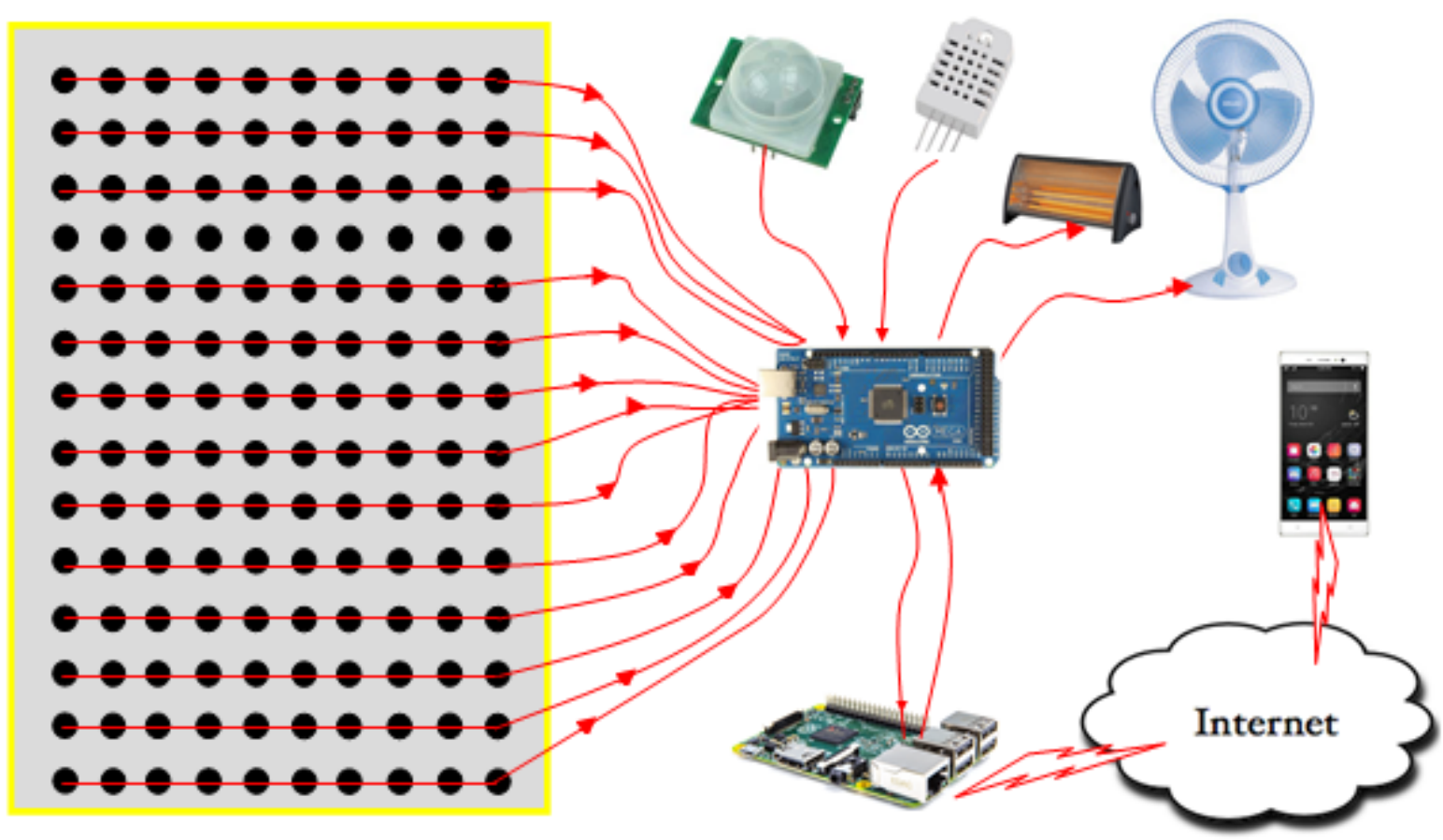

Gambar 1. Desain perancangan sistem

Pada perancangan sistem terdapat tiga bagian yaitu input, proses dan output. Input pada sistem ini adalah dari sensor limit switch pada karpet, sensor pir, dan sensor suhu. Input sensor limit switch pada karpet berfungsi untuk mendeteksi aktivitas lansia pada saat berdiri, berjalan, duduk dan berbaring menggunakan algoritma greedy [1][2]. Saat lansia melakukan aktivitas di atas karpet maka secara otomatis limit switch akan tertekan dan menghasilkan data yang akan dikontrol oleh media proses. Sensor PIR berfungsi untuk mendeteksi pergerakan lansia dalam ruangan serta sensor suhu DHT22 berfungsi untuk mendeteksi suhu dalam ruangan. Data yang di deteksi oleh semua sensor kemudian akan diproses pada Arduino Mega [1][2] dan Raspberry Pi. Fungsi Arduino Mega untuk mengontrol input data sensor serta mengontrol output kipas dan pemanas ruangan. Untuk mengontrol nyala kipas dan pemanas ruangan Arduino Mega mengirim sinyal 1 (high) ke peralatan elektronik untuk menyalakan dan sinyal 0 (low) untuk mematikannya. Terdapat rangkaian relay yang digunakan untuk mengontrol nyala dan mati dari peralatan elektronik tersebut.

Seluruh informasi data sensor yang terhubung ke Arduino Mega kemudian di hubungkan ke Raspberry Pi menggunakan komunikasi serial USB. Fungsi Raspberry Pi adalah untuk mengolah 
informasi data sensor dari Arduino Mega agar dapat terkirim ke server menggunakan jaringan internet. Raspberry Pi merupakan sebuah mikrokomputer yang berukuran seperti kartu kredit dan dilengkapi dengan processor, RAM, Video output serta port GPIO untuk pengontrolannya. Raspberry $\mathrm{Pi}$ banyak digunakan untuk sistem kontrol dan teknik komputasi lainnya seperti teknik pengolahan citra karena sistem kerjanya sama seperti komputer [6]. Pada Raspberry Pi dan server terdapat konfigurasi node.js yang bersungsi sebagai socket untuk menghubungkan semua informasi data ke Internet. Semua informasi data yang tersimpan di server internet kemudian akan ditampilkan di website yaitu berupa informasi lansia pada saat berdiri, duduk, berjalan dan berbaring serta informasi kondisi ruangan.

Pada saat keluarga atau penjaga lansia ingin melihat aktivitas lansia maka mereka cukup membukan laman website dari sistem yang sudah dikonfigurasi kemudian melihat informasi aktivitas lansia sesuai dengan yang ditampilkan pada website. Selain melihat informasi aktivitas dan kondisi ruangan, pengguna juga dapat mengontrol on dan off peralatan elektronik rumah seperti kipas dan pemanas ruangan. Fungsi dari sistem ini untuk membantu lansia mengontrol kondisi suhu ruangan agar lansia merasa nyaman saat berada dalam ruangan. Pengguna cukup menekan tombol on dan off pada website untuk mengontrol peralatan rumah tangga tersebut. Perintah yang diterima dari website kemudian di kirim ke Raspberry Pi menggunakan jaringan internet, setelah itu memerintahkan Arduino mega untuk mematikan atau menyalakan peralatan elektronik menggunakan perintah 1 untuk on dan 0 untuk off.

\subsection{Internet of Things (loT)}

Menurut beberapa referensi, Internet of Thing (IoT) adalah menghubungkan beberapa objek, device, mesin, peralatan, sensor dan beberapa benda fisik lainnya untuk dapat saling berkomunikasi dan bertukar data menggunakan jaringan internet. Hal ini memungkinkan untuk peralatan, device dan mesin dapat bekerja dan berkomunikasi secara otomatis dengan maksud dan tujuan yang sama [7][8]. IoT merupakan pengembangan ilmu di bidang jaringan, sensor dan sistem kontrol yang saling terhubung untuk memberikan informasi dari objek atau keadaan di sekitarnya menggunakan jaringan internet [9]. Saat ini teknologi loT terus mengalami pengembangan dan merupakan teknologi masa depan yang terus digunakan unutk memberikan informasi berdasarkan input dari sensor dan sistem kontrol.

Fungsi loT dalam penelitian ini adalah untuk menghubungkan semua informasi data sensor ke server menggunakan jaringan internet dan di tampilkan ke website sebagai media informasi dari aktivitas lansia. Informasi data yang terdeteksi oleh sensor merupakan hasil dari seluruh aktivitas lansia dan dapat di akses secara realtime oleh penjaga lansia menggunakan teknologi loT. Selain untuk menampilkan informasi lansia, loT ini juga digunakan untuk mengontrol peralatan elektronik yang ada di rumah yaitu kipas dan pemanas ruangan, peneliti menggunakan tools node.js sebagai socket penghubung antara client ke server internet. Node.js adalah perangkat lunak berbasis web menggunakan bahasa pemrograman java script yang dapat berjalan pada aplikasi server dan client secara realtime.

\section{Hasil dan Pembahasan}

Hasil dari penelitian ini adalah berupa sistem informasi yang dapat mendeteksi aktivitas lansia yang berada di dalam ruangan berdasarkan informasi dari karpet dan sensor. Karpet yang dirancang berukuran lebar $120 \mathrm{~cm}$ dan panjang $240 \mathrm{~cm}$. Sistem terbuat dari beberapa bagian yang saling terhubung yaitu sensor limit switch pada karpet, Arduino Mega, komponen elektronika, Raspberry Pi, sensor PIR, sensor suhu DHT22 dan koneksi Internet. Semua komponen tersebut di satukan hingga terbentuk suatu sistem kontrol informasi aktivitas lansia berbasis Internet of Things.

Sistem yang dirancang pada penelitian ini hanya dapat mendeteksi aktivitas lansia dalam satu ruangan. Pada gambar 2 merupakan hasil dari perancangan alat dan karpet yang dibangun untuk mendeteksi seluruh aktivitas lansia yang berada di dalam ruangan. Gambar tersebut memperlihatkan hasil perancangan karpet tampak atas dan tampak bawah. Di bagian bawah karpet terdapat node sensor limit switch yang berfungsi untuk mendeteksi aktivitas lansia diatas karpet. Node sensor ini akan aktif pada saat lansia menginjak sensor limit switch. Sensor PIR dan sensor suhu DHT22 diletakkan pada bagian tertentu yang mudah untuk medeteksi aktivitas lansia dan suhu ruangan. 


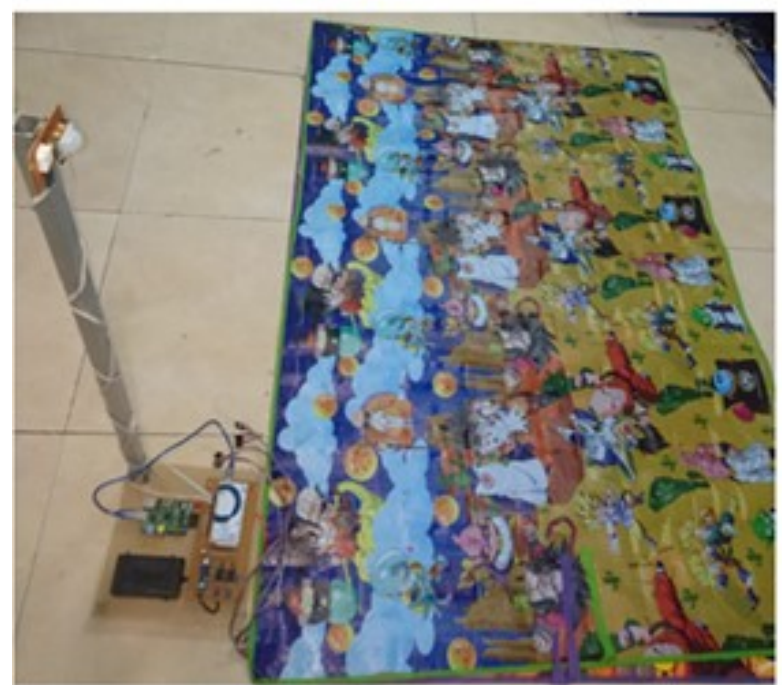

(a)

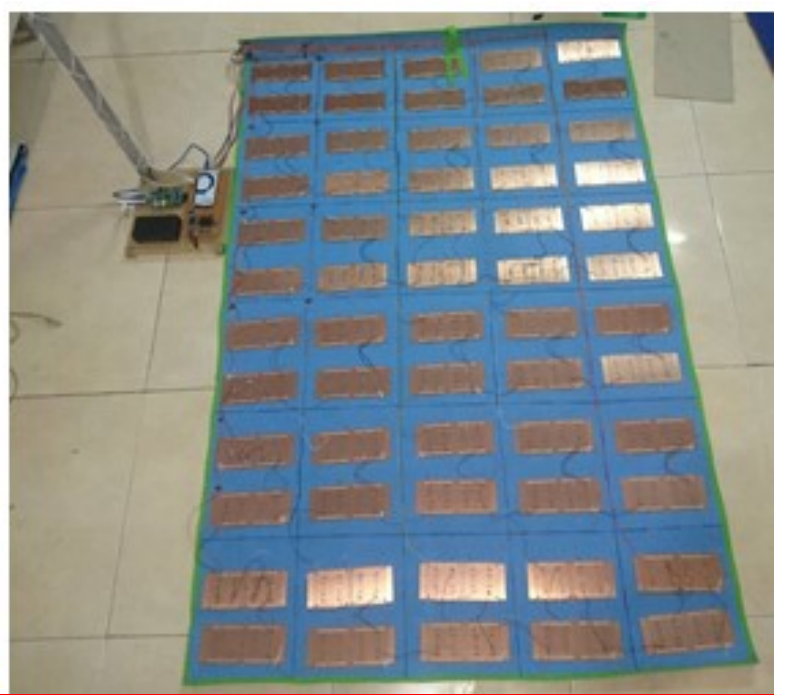

(b)

Gambar 2. Hasil perancangan sistem dan karpet tampak atas (a) dan bawah (b).

Dalam penelitian ini semua informasi data dari sensor akan diproses pada Arduino Mega menggunakan algoritma greedy kemudian dihubungkan ke Raspberry Pi. Raspberry Pi berfungsi untuk menghubungkan data dari Arduino ke internet dan dari internet ke Arduino menggunakan sistem konfigurasi node.js. Alasan peneliti menggunakan algoritma tersebut karena sifatnya yang rakus dalam menentukan titik terdekat, sehingga akan sangat efisien jika digunakan untuk mendeteksi aktivitas lansia diatas karpet berdasarkan jumlah titik node sensor yang tertekan. Pada penelitian ini terdapat 30 titik node sensor yang saling terhubung dan dapat mengirimkan data ketika sensor tersebut di tekan.

Sensor suhu DHT22 yang digunakan pada sistem ini berfungsi untuk mendeteksi suhu dalam ruangan sehingga berdasarkan informasi tersebut pengguna dapat mengontrol keadaan suhu dengan menyalakan atau mematikan kipas dan pemanas ruangan secara otomatis dan manual. Sensor PIR pada penelitian ini berfungsi untuk mendeteksi pergerakan lansia, hal ini bertujuan untuk mengetahui pada saat lansia sedang tidur atau berbaring, jika terdapat gerakan maka lansia sedang tidur, tapi jika tidak ada gerakan dalam waktu yang lama maka dikhawatirkan terjadi sesuatu yang tidak diinginkan pada lansia. Pada gambar 3 merupakan hasil dari perancangan elektronik dan sistem kontrol yang telah dibangun. Gambar (a) memperlihatkan jenis sensor suhu dan sensor PIR yang digunakan dan gambar (b) terdapat arduino mega dan Raspberry Pi sebagai komponen sistem kontrol dan komponen elektronika lainnya seperti power supply, rangkaian pengatur daya dan rangkaian driver relay.

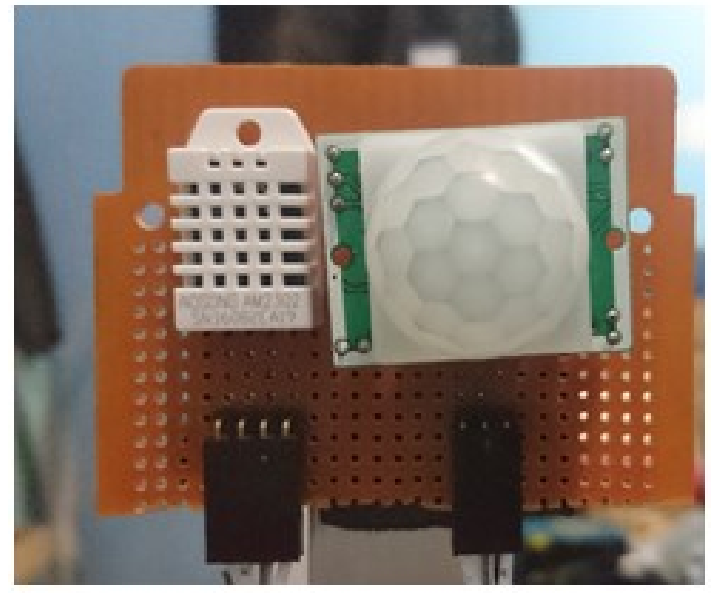

(a)

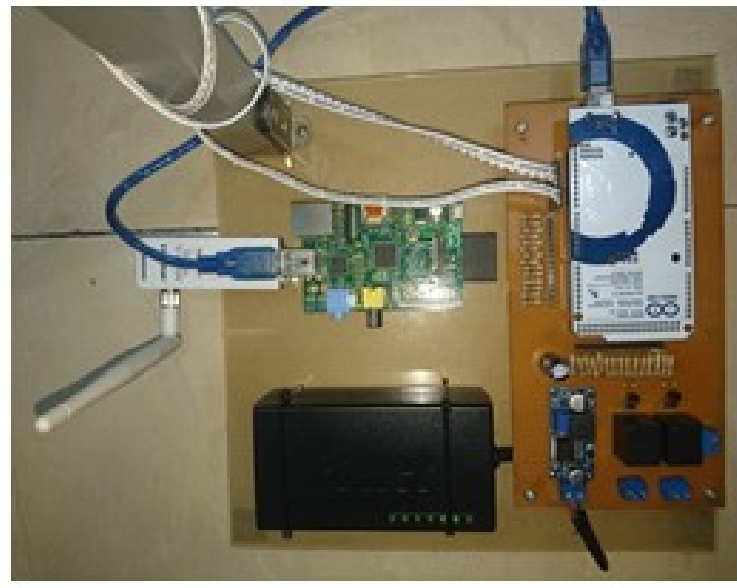

(b)

Gambar 3. (a) Sensor PIR dan sensor suhu DHT22, (b) Rangkaian sistem kontrol 


\section{ILKOM Jurnal Ilmiah Volume 10 Nomor 2 Agustus 2018}

Data yang terdeteksi oleh sensor dapat di monitor secara realtime. Data-data tersebut kemudian dikirim ke server dan akan ditampilkan pada website. Berikut adalah tabel konfigurasi dari hasil deteksi aktivitas lansia yang terkirim ke server menggunakan jaringan internet.

Tabel 1. Konfigurasi hasil deteksi sensor dan kontrol sistem..

\begin{tabular}{|c|l|l|l|}
\hline No & \multicolumn{1}{|c|}{ Konfigurasi } & \multicolumn{1}{|c|}{ Kondisi } & \multicolumn{1}{c|}{ Keterangan } \\
\hline 1 & Data suhu & $0-100 \mathrm{C}$ & Nilai suhu ruangan \\
\hline 2 & Data lembab & $0-100 \mathrm{C}$ & Nilai kelembaban ruangan \\
\hline 3 & Data lantai & 3 Kondisi & Lansia berdiri, duduk atau berbaring \\
\hline 4 & Data kipas & 1 atau 0 & Kondisi kipas on (1) atau off (0) \\
\hline 5 & Data pemanas & 1 atau 0 & Kondisi pemanas on (1) atau off (0) \\
\hline 6 & Data PIR & 1 atau 0 & Deteksi aktivitas (1) atau tidak beraktivitas (0) \\
\hline 7 & Data otomatis & 1 atau 0 & Aktif (1) atau tidak aktif (0) \\
\hline 8 & Data suhu maksimal & Input data & Suhu maksimum deteksi sensor \\
\hline 9 & Data suhu minimal & Input data & Suhu minimum deteksi sensor \\
\hline
\end{tabular}

Pada saat penjaga lansia berada diluar ruangan, mereka dapat melihat aktivitas lansia dengan mengakses laman web yang telah di konfigurasi oleh sistem. Pengguna cukup menggunakan handphone atau komputer kemudian membuka aplikasi web browser dan memasukkan alamat URL dari sistem informasi aktivitas lansia. Berikut adalah hasil tampilan website dari perancangan sistem informasi deteksi aktivitas lansia menggunakan jaringan internet.

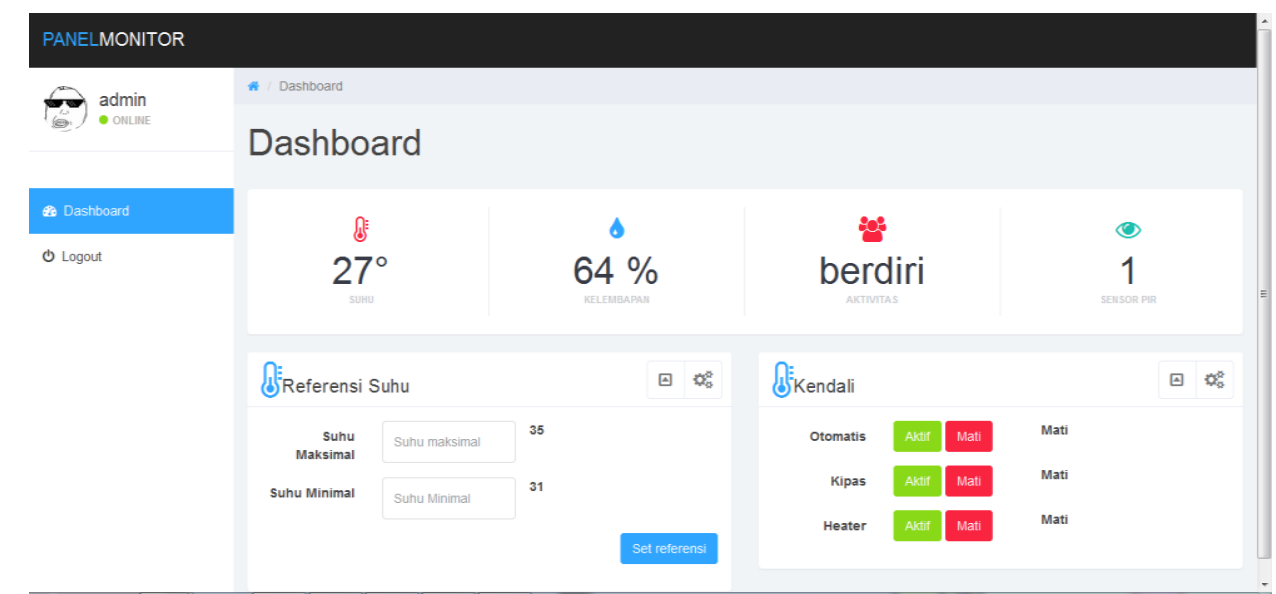

Gambar 4. Informasi lansia pada saat sedang berdiri

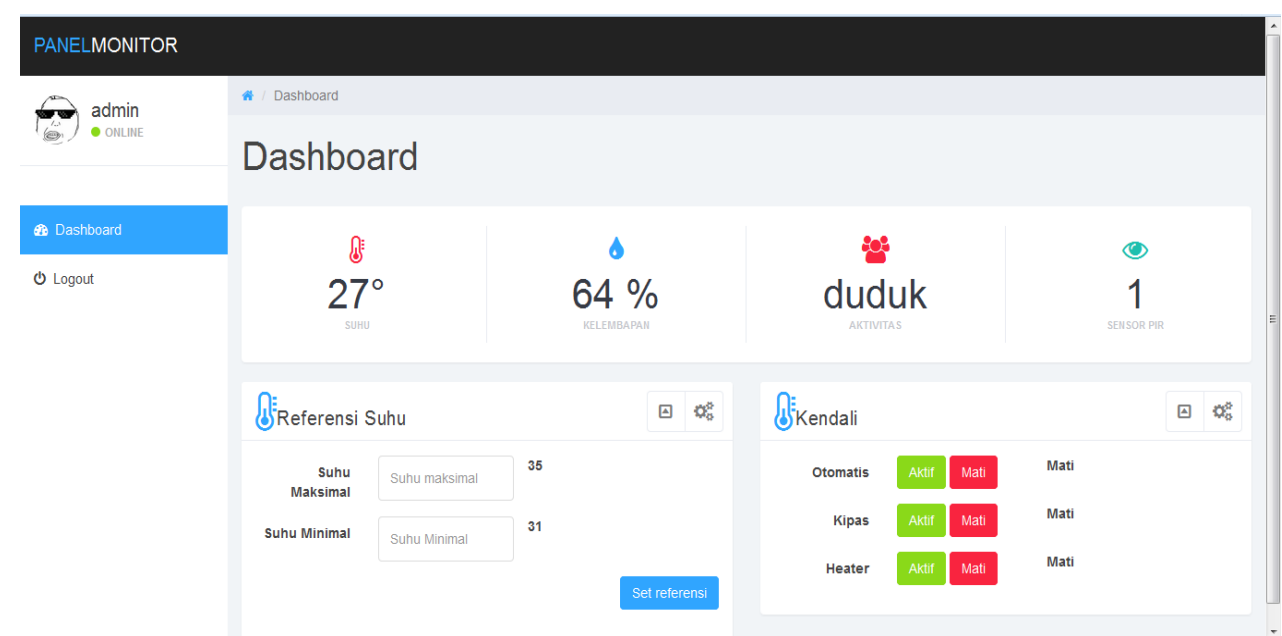

Gambar 5. Informasi lansia pada saat sedang duduk 


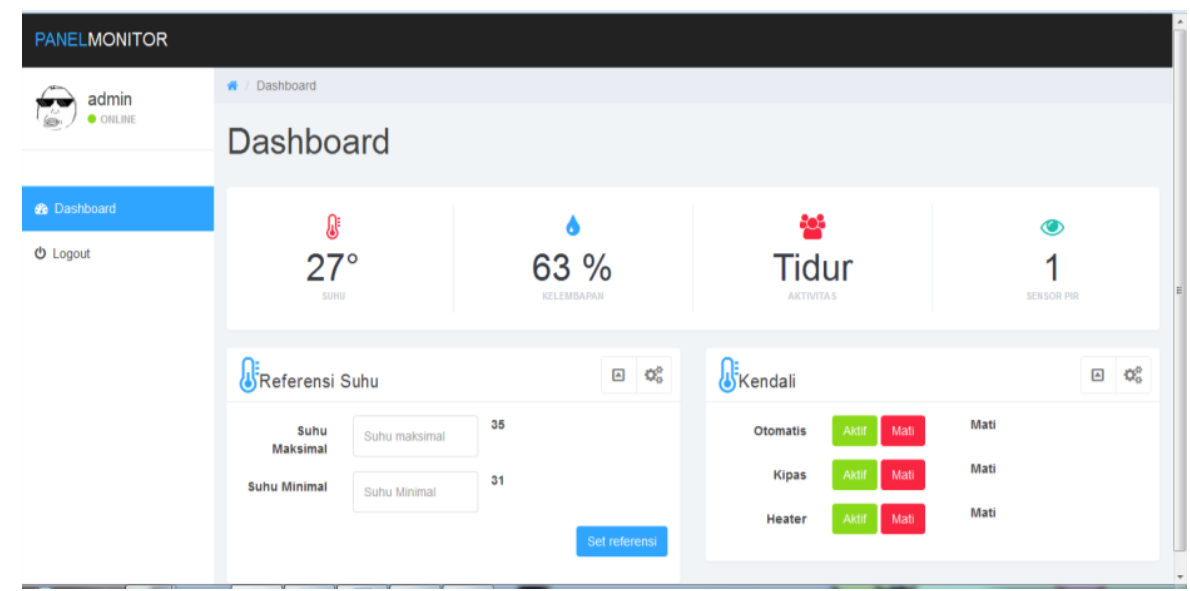

Gambar 6. Informasi lansia pada saat sedang tidur

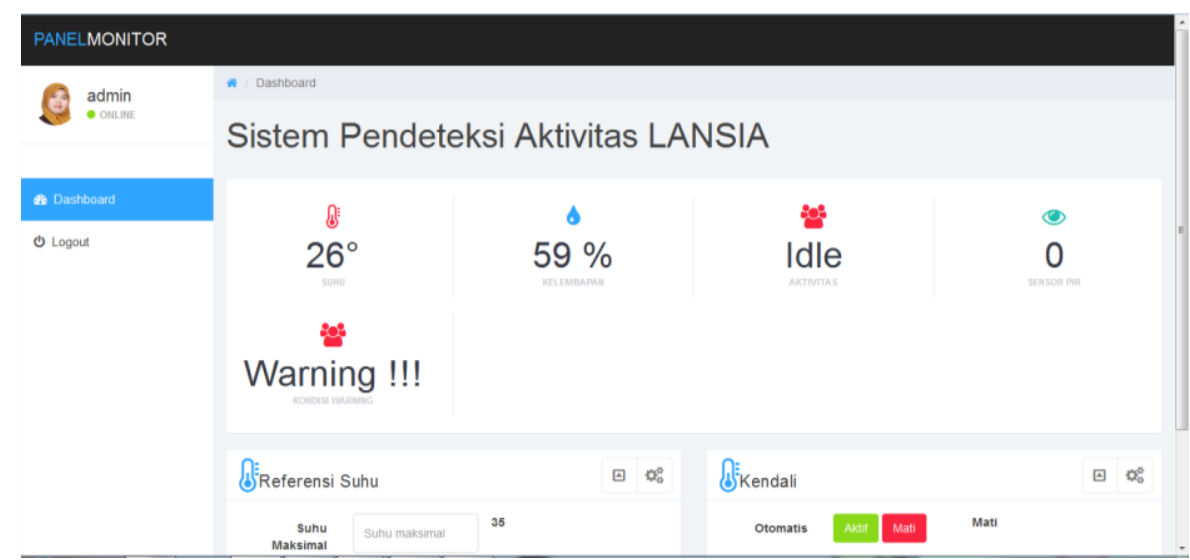

Gambar 7. Informasi pada saat sistem tidak mendeteksi aktivitas lansia.

Pada gambar 4, 5, 6 dan 7 menunjukkan hasil penelitian dan informasi yang ditampilkan pada website dalam mendeteksi aktivitas lansia pada saat berdiri, duduk dan berbaring. Selain itu sistem dapat memberikan informasi pada saat lansia tidak sedang melakukan aktivitas di atas karpet atau di ruangan dengan memunculkan pesan "warning", hal ini bertujuan untuk memberikan pesan kepada penjaga lansia ketika terjadi sesuatu yang tidak diinginkan oleh lansia karena tidak adanya aktivitas yang dideteksi oleh sistem. Kondisi ini terpenuhi ketika sistem tidak mendeteksi aktivitas lansia di atas karpet dan pergerakan dari sensor PIR. Pesan warning juga mengidentifikasi bahwa lansia dalam keadaan tidak aman.

Selain informasi aktivitas lansia, pengguna juga dapat melihat kondisi suhu dan kelembaban ruangan. Pengguna dapat mengontrol on dan off perangkat elektronik secara manual dengan cara menekan tombol "on" atau "off" pada laman website. Pada saat tombol on ditekan maka akan memerintahkan sistem untuk menyalakan kipas atau pemanas ruangan, jika tombol off ditekan maka akan memerintahkan sistem untuk mematikan kipas atau pemanas ruangan. Pengguna juga dapat mengkonfigurasi sistem dari jarak jauh agar kipas dan pemanas dapat beroperasi secara otomatis berdasarkan input nilai minimum dan maksimum suhu ruangan. Jika suhu maksimum, maka kipas akan menyala secara otomatis dan jika mencapai suhu minimum maka pemanas ruangan akan menyala otomatis. Jika kondisi suhu dalam keadaan normal maka kipas dan pemanas dalam keadaan tidak aktif.

Pada tabel 2 merupakan hasil pengujian sistem kontrol dari nilai yang ditampilkan pada website. Pengujian tersebut dilakukan pada saat lansia sedang melakukan aktivitas berdiri, duduk, berbaring, dan tidak melakukan aktivitas. Nilai tersebut di ambil berdasarkan hasil konfigurasi dari sistem yang telah dibangun. Selain mendeteksi aktivitas lansia, pengujian sistem juga dilakukan untuk mendeteksi keadaan suhu ruangan. Nilai kelembaban suhu akan ditampilkan pada website sesuai dengan keadaan suhu didalam ruangan. Jika suhu panas maka kipas akan menyala, jika suhu dingin maka pemanas akan menyala. Sistem juga dapat dikontrol secara otomatis melalui website. 
ILKOM Jurnal IImiah Volume 10 Nomor 2 Agustus 2018

Tabel 2. Hasil pengujian sistem kontrol berdasarkan nilai output pada website

\begin{tabular}{|c|c|c|c|}
\hline Informasi Data & Informasi Nilai & Kondisi & Kesimpulan \\
\hline Suhu & 27 & Suhu normal & \multirow{7}{*}{$\begin{array}{l}\text { Lansia sedang } \\
\text { melakukan aktivitas } \\
\text { berdiri dan kondisi } \\
\text { suhu ruangan dalam } \\
\text { keadaan baik. }\end{array}$} \\
\hline Kelembapan & $64 \%$ & Kelembapan udara & \\
\hline Aktivitas & Berdiri & Lansia berdiri & \\
\hline Sensor PIR & 1 & Deteksi aktivitas & \\
\hline Kondisi Warning & - & Kondisi lansia aman & \\
\hline Referensi suhu & Max 35, Min 31 & Referensi suhu kendali & \\
\hline Kendali & Semua Off & Kipas dan pemanas off & \\
\hline Suhu & 27 & Suhu normal & \multirow{7}{*}{$\begin{array}{l}\text { Lansia sedang } \\
\text { melakukan aktivitas } \\
\text { duduk dan kondisi suhu } \\
\text { ruangan dalam } \\
\text { keadaan baik. }\end{array}$} \\
\hline Kelembapan & $64 \%$ & Kelembapan udara & \\
\hline Aktivitas & Duduk & Lansia duduk & \\
\hline Sensor PIR & 1 & Deteksi aktivitas & \\
\hline Kondisi Warning & - & Kondisi lansia aman & \\
\hline Referensi suhu & Max 35, Min 31 & Referensi suhu kendali & \\
\hline Kendali & Semua Off & Kipas dan pemanas off & \\
\hline Suhu & 27 & Suhu normal & \multirow{7}{*}{$\begin{array}{l}\text { Lansia sedang } \\
\text { melakukan aktivitas } \\
\text { berbaring dan kondisi } \\
\text { suhu ruangan dalam } \\
\text { keadaan baik. }\end{array}$} \\
\hline Kelembapan & $63 \%$ & Kelembapan udara & \\
\hline Aktivitas & Tidur & Lansia berbaring & \\
\hline Sensor PIR & 1 & Deteksi aktivitas & \\
\hline Kondisi Warning & - & Kondisi lansia aman & \\
\hline Referensi suhu & Max 35, Min 31 & Referensi suhu kendali & \\
\hline Kendali & Semua Off & Kipas dan pemanas off & \\
\hline Suhu & 26 & Suhu normal & \multirow{7}{*}{$\begin{array}{l}\text { Lansia tidak melakukan } \\
\text { aktivitas dalam waktu } \\
\text { yang lama dan } \\
\text { dikhawatirkan terjadi } \\
\text { sesuatu yang tidak } \\
\text { diinginkan pada lansia } \\
\text { atau tidak aman. }\end{array}$} \\
\hline Kelembapan & $59 \%$ & Kelembapan udara & \\
\hline Aktivitas & Idle & Tidak ada aktivitas & \\
\hline Sensor PIR & 0 & Tidak deteksi aktivitas & \\
\hline Kondisi Warning & Warning on & Kondisi lansia tidak aman & \\
\hline Referensi suhu & Max 35, Min 31 & Referensi suhu kendali & \\
\hline Kendali & Semua Off & Kipas dan pemanas off & \\
\hline Suhu & 35 & Suhu Panas & \multirow{7}{*}{$\begin{array}{l}\text { Lansia melakukan } \\
\text { aktivitas berdiri, suhu } \\
\text { ruangan panas, kipas } \\
\text { dalam ruangan } \\
\text { menyala. }\end{array}$} \\
\hline Kelembapan & $55 \%$ & Kelembapan udara & \\
\hline Aktivitas & Berdiri & Lansia berdiri & \\
\hline Sensor PIR & 1 & Deteksi aktivitas & \\
\hline Kondisi Warning & - & Kondisi lansia aman & \\
\hline Referensi suhu & Max 35, Min 31 & Referensi suhu kendali & \\
\hline Kendali & Kipas On & Kipas On & \\
\hline Suhu & 25 & Suhu dingin & \multirow{7}{*}{$\begin{array}{l}\text { Lansia melakukan } \\
\text { aktivitas berbaring, } \\
\text { suhu ruangan dingin, } \\
\text { mode otomasi aktif, } \\
\text { pemanas menyala. }\end{array}$} \\
\hline Kelembapan & $69 \%$ & Kelembaban udara & \\
\hline Aktivitas & Tidur & Lansia berbaring & \\
\hline Sensor PIR & 1 & Deteksi aktivitas & \\
\hline Kondisi Warning & - & Kondisi lansia aman & \\
\hline Referensi suhu & Max 35, Min 31 & Kendali otomatis aktif & \\
\hline Kendali & Otomatis aktif & Pemanas on & \\
\hline Suhu & 36 & Suhu panas & \multirow{7}{*}{$\begin{array}{l}\text { Lansia melakukan } \\
\text { aktivitas berbaring, } \\
\text { suhu ruangan panas, } \\
\text { mode otomasi aktif, } \\
\text { kipas menyala. }\end{array}$} \\
\hline Kelembapan & $45 \%$ & Kelembaban udara & \\
\hline Aktivitas & Tidur & Lansia berbaring & \\
\hline Sensor PIR & 1 & Deteksi aktivitas & \\
\hline Kondisi Warning & - & Kondisi lansia aman & \\
\hline Referensi suhu & Max 35, Min 31 & Kendali otomatis aktif & \\
\hline Kendali & Otomatis aktif & Kipas menyala & \\
\hline
\end{tabular}

Fungsi informasi data yang ditampilkan pada website merupakan informasi dari seluruh aktivitas dan sistem yang berjalan. Berikut adalah tabel penjelasan dari informasi data yang ditampilkan pada website. 
Tabel 3. Hasil pengujian sistem kontrol berdasarkan nilai output pada website

\begin{tabular}{|c|c|}
\hline Informasi Data & Keterangan \\
\hline Suhu & Informasi kondisi suhu dalam ruangan \\
\hline Kelembapan & Informasi kelembapan udara yang ada di dalam ruangan \\
\hline Aktivitas & Informasi aktivitas lansia saat berdiri, berjalan dan berbaring \\
\hline Sensor PIR & Informasi mendeteksi pergerakan lansia saat tertidur \\
\hline Kondisi Warning & Informasi peringatan pada saat sistem tidak mendeteksi aktivitas lansia \\
\hline Referensi suhu & Nilai suhu maksimum dan minimum untuk mengaktifkan sistem kendali otomatis \\
\hline Kendali & $\begin{array}{l}\text { Tombol untuk menyalakan dan mematikan kipas atau pemanas serta } \\
\text { mengaktifkan sistem kendali otomatis }\end{array}$ \\
\hline
\end{tabular}

\section{Kesimpulan dan Saran}

Hasil dari penelitian ini sistem dapat memberikan informasi aktivitas lansia kepada keluarga atau penjaga lansia secara online menggunakan website berbasis loT. Sistem dapat menampilkan informasi lansia saat berdiri, duduk, dan berbaring serta kondisi suhu dan aktivitas pergerakan dari lansia. Pengguna juga dapat mengontrol peralatan elektronik berupa kipas dan pemanas ruangan secara manual dan otomatis melalui tombol yang disediakan pada website. Sensor limit switch pada karpet dapat mendeteksi aktivitas lansia secara realtime, namun penggunaan sensor limit switch yang begitu banyak membuat lansia merasa kurang nyaman karena tonjolan sensor pada karpet. Pergerakan lansia pada saat tidur dapat terdeteksi menggunakan sensor PIR dengan jarak deteksi maksimum hingga 10 meter. Suhu ruangan dapat terdeteksi menggunakan sensor DHT22 dengan nilai referensi suhu sesuai dengan kondisi suhu ruangan. Seluruh informasi data sensor diproses oleh Arduino mega dan terkirim ke server secara online menggunakan Raspberry Pi. Sistem yang digunakan untuk menghubungkan data dari Raspberry $\mathrm{Pi}$ ke server online adalah menggunakan konfigurasi node.js. Pengguna juga dapat mengontrol on dan off perangkat elektronik secara online serta mengatur konfigurasi sistem kontrol agar dapat berjalan secara otomatis.

Pengembangan sistem pada penelitian selanjutnya adalah desain sensor yang ada pada karpet dapat didesain lebih fleksibel agar nyaman untuk digunakan oleh lansia, selain itu informasi yang diberikan dapat dikembangkan untuk mendeteksi kondisi kesehatan dari lansia. Sistem keamanan informasi lansia juga perlu dilindungi agar tidak mudah untuk di sadap oleh pihak yang tidak bertanggungjawab.

\section{Daftar Pustaka}

[1] P. Wahyuningsih, "Rancang Bangun Sistem Deteksi Aktivitas Lansia Berbasis Arduino Mega," vol. 8, no. 2, pp. 102-108, 2017.

[2] P. Wahyuningsih, "Penerapan Algoritma Greedy Untuk Mendeteksi Aktivitas Lansia Pada Karpet Menggunakan Arduino Mega," vol. 3, no. April, pp. 51-60, 2018.

[3] S. Sulandari, "Bentuk-Bentuk Produktivitas," Indig. J. Ilm. Berk. Psikol., vol. 11, no. 1, pp. 5868, 2009.

[4] M. Sauliyusta and E. Rekawati, "Aktivitas Fisik Memengaruhi Fungsi Kognitif Lansia," J. Keperawatan Indones., vol. 19, no. 2, pp. 71-77, 2016.

[5] D. Kartikasari, F. Handayani, K. Fakultas, and K. Universitas, "Pemenuhan Kebutuhan Dasar Manusia Pada Lansia Demensia Oleh Keluarga," J. Nurs. Stud., vol. 1, 2012.

[6] Abdul Jalil, "Pengolahan Citra Mendeteksi Keaslian Uang Kertas Rupiah Mengunakan Raspberry PI," Jurnal IT STMIK Handayani, vol. 14, pp. 13-19, 2014.

[7] E. D. Meutia, "Internet of Things - Keamanan dan Privasi," Semin. Nas. dan Expo Tek. Elektro 2015, pp. 85-89, 2015.

[8] R. N. Chandra, "Internet of Things dan Embedded System Untuk Indonesia," Univ. Surya, p. 40, 2014.

[9] A. Junaidi, "Internet of Things, Sejarah, Teknologi Dan Penerapannya: Review," Jurnal IImiah Teknologi Informasi Terapan Volume I, No 3, p. 62-66, 2015. 